\title{
Microstructure and Mechanical Properties of Ti-6Al-4V Parts Fabricated by Electron Beam Melting under Dynamic Compression Tests
}

\author{
Reza Alaghmandfard ${ }^{1}$, Dharmendra Chalasani ${ }^{1}$, Akindele Odeshi ${ }^{2}$, Mohsen Mohammadi ${ }^{1}$ \\ ${ }^{1}$ Marine Additive Manufacturing Centre of Excellence (MAMCE), University of New Brunswick, Fredericton, NB, E3B 5A1, Canada \\ ${ }^{2}$ Department of Mechanical Engineering, University of Saskatchewan, Saskatoon, SK S7N 5A9, Canada \\ Reza.alaghmand@unb.ca
}

\begin{abstract}
In this research, the effect of strain rate on the microstructure evolution, mechanical properties, and deformation mechanisms of the horizontally printed Ti-6Al-4V cylindrical rods produced by electron beam melting (EBM) was investigated. The initial microstructure consists of $\alpha$ and $\beta$ phases, and columnar prior $\beta$-grain boundaries oriented along the building direction. Dynamic compression tests at three different strain rates $\left(690 \mathrm{~s}^{-1}, 1580 \mathrm{~s}^{-1}\right.$, and $\left.2220 \mathrm{~s}^{-1}\right)$ were performed using a Split-Hopkinson pressure bar (SHPB) apparatus. The variations in dynamic mechanical properties were correlated with the microstructural features such as $\alpha$ platelet width, interlamellar spacing, and fragmentation. Adiabatic shear bands (ASBs) formed in the thermally softened areas in the samples deformed at higher strain rates, which led to the fracture. The fracture of test specimen at high strain rates is attributed to the formation of voids and their subsequent growth and coalescence under thermal instability along the adiabatic shear bands during deformation. In the fractured samples, features of both ductile (presence of dimples) and brittle (smoother surfaces) were observed. With the increase in strain rate from $690 \mathrm{~s}^{-1}$ to $2220 \mathrm{~s}^{-1}$, yield strength (YS), ultimate compressive strength (UCS), and strain-to-fracture increased by $48 \%, 28 \%$, and $286 \%$.
\end{abstract}

Keywords: Ti-6Al-4V, Electron beam melting (EBM), SplitHopkinson pressure bar (SHPB), Deformation mechanisms, Adiabatic Shear Bands (ASBs)

\section{INTRODUCTION}

Titanium alloys, especially Ti-6Al-4V, exhibit a good combination of corrosion resistance, toughness, biocompatibility, and strength-to-weight ratio [1, 2]. However, the high affinity of this alloy to oxygen and the high cost of machining make the final cost of this alloy to be high [3]. Additive manufacturing (AM) is a new method for the fabrication of complex parts from a 3D design without a need for costly tools [4]. In the present study, the Ti-6Al-4V rods were fabricated by electron beam melting (EBM) technique. One of the advantages of EBM compared to other additive processes is the use of a vacuum atmosphere that prevents oxygen entrapment [5]. Conventionally fabricated Ti-6Al-4V parts contain two main phases, $\alpha$-phase, and $\beta$-phase, present in
$95 \%$ and $5 \%$, respectively. Due to the high cooling rates in EBM-process, the $\beta$-phase fraction is expected to be high. However, the powder bed is maintained at high build temperature (typically at $650{ }^{\circ} \mathrm{C}$ ), which is akin to the heattreatment to transform the $\beta$ into $\alpha$ [6]. As a result, in EBM- Ti$6 \mathrm{Al}-4 \mathrm{~V}$, the $\alpha$-phase fraction increases to $99.8 \%$, while the volume fraction of $\beta$-phase can be as low as $0.2 \%$ [7]. There are many studies on the dynamic deformation behavior of Ti$6 \mathrm{Al}-4 \mathrm{~V}$ fabricated by conventional methods [8, 9], but there is minimal work on the EBM-Ti-6Al-4V. In this study, the effect of strain rate on the microstructure and dynamic mechanical properties, and the corresponding deformation mechanisms in the EBM-Ti-6Al-4V alloy were studied.

\section{MATERIAL \& SETUP}

An ARCAM EBM Q10 system was used to fabricate horizontal rods with a diameter of $9.5 \mathrm{~mm}$ and a height of $120 \mathrm{~mm}$ using Ti-6Al-4V Grade 5 powder with size in $40-100 \mu \mathrm{m}$ range. The nominal composition and the recommended process parameters by Arcam are shown in Tables 1 and 2, respectively. Cylindrical samples $(9.5 \mathrm{~mm}$ diameter and $10.4 \mathrm{~mm}$ height) were machined as shown schematically in Fig.1 for dynamic compression tests, and the hatched surface was used for microstructural studies.

Table 1- The nominal composition of Grade 5 Ti-6Al-4V powder.

\begin{tabular}{|c|c|c|c|c|c|c|c|}
\hline $\mathbf{A l}$ & $\mathbf{V}$ & $\mathbf{F e}$ & $\mathbf{O}$ & $\mathbf{C}$ & $\mathbf{N}$ & $\mathbf{H}$ & $\mathbf{T i}$ \\
\hline $6 \%$ & $4 \%$ & $0.1 \%$ & $0.15 \%$ & $0.03 \%$ & $0.01 \%$ & $0.003 \%$ & Balanced \\
\hline
\end{tabular}

Table 2- Recommended EBM process parameters by Arcam.

\begin{tabular}{|c|c|c|c|c|}
\hline $\begin{array}{c}\text { Layer } \\
\text { thickness }\end{array}$ & $\begin{array}{c}\text { Layer } \\
\text { orientation }\end{array}$ & $\begin{array}{c}\text { Beam spot } \\
\text { size }\end{array}$ & $\begin{array}{c}\text { Hatch } \\
\text { distance }\end{array}$ & $\begin{array}{c}\text { Bed } \\
\text { temperature }\end{array}$ \\
\hline $50 \mu \mathrm{m}$ & $46^{\circ}$ & $450-500 \mu \mathrm{m}$ & $0.2 \mathrm{~mm}$ & $650-700^{\circ} \mathrm{C}$ \\
\hline
\end{tabular}

A Split-Hopkinson pressure bar (SHPB) apparatus was used to conduct impact tests on the machined cylindrical samples. The schematic of the SHPB in Fig. 2 shows different parts of this apparatus. A striker fires is fired by a light gas gun to hit incident bar. The generated elastic wave, when the striker 
hits the incident bar, passes through the incident bar, the sample, and the transmitted bar. Some portion of the wave deforms the sample, and the rest of the wave reflects and propagates away from the first with the test specimen through the incident bar. The strain gauges on the bars capture the incident $\left(\varepsilon_{\mathrm{I}}\right)$, transmitted $\left(\varepsilon_{\mathrm{T}}\right)$, and reflected $\left(\varepsilon_{\mathrm{R}}\right)$ waves.

The true stress, true strain, and true strain rate in Eq. 4 to Eq. 6 are derived from the nominal stress, nominal strain, and nominal strain rate in Eq. 1 to Eq. 3, which are generated from elastic waves obtained from the SHPB test.

$$
\begin{aligned}
& \sigma_{\text {nominal }}=\left(A_{\text {bar }} / A_{\text {sample }}\right) E_{\text {Young }} \cdot \varepsilon_{T} \\
& \dot{\varepsilon}_{\text {nominal }}=-2\left(C_{\text {bar }} / L_{\text {sample }}\right) \varepsilon_{R} \\
& \varepsilon_{\text {nominal }}=\int_{0}^{t} \dot{\varepsilon}_{\text {nominal }} d t \\
& \sigma_{\text {true }}=\sigma_{\text {nominal }}\left(1-\varepsilon_{\text {nominal }}\right) \\
& \varepsilon_{\text {true }}=-\ln \left(1-\varepsilon_{\text {nominal }}\right) \\
& \dot{\varepsilon}_{\text {true }}=\dot{\varepsilon}_{\text {true }} /\left(1-\varepsilon_{\text {nominal }}\right)
\end{aligned}
$$

where $A_{\text {bar, }} A_{\text {sample, }}$ EYoung, $\mathrm{C}_{\text {bar }}$, and $\mathrm{L}_{\text {sample }}$ are the initial cross-sections of the bars, sample, Young's modulus, the wave velocity in the bars and the initial length of the sample, respectively [9].

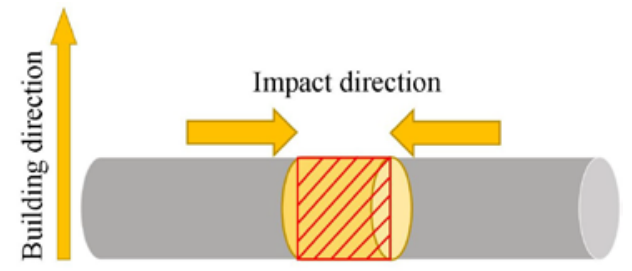

Figure 1- Schematic of printed rods. The hatched surface is considered for microstructural investigations.

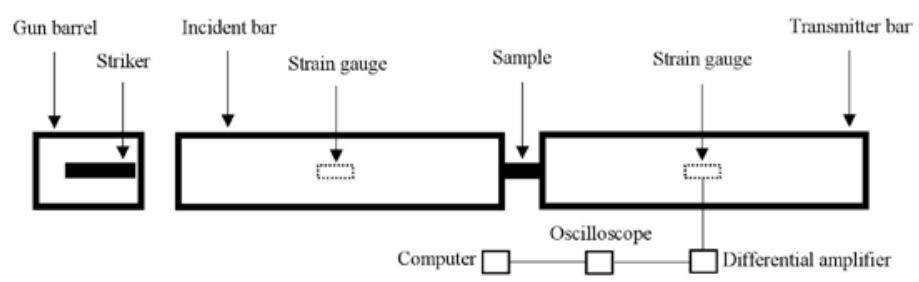

Figure 2- Split-Hopkinson apparatus used to perform the dynamic compression tests.

The typical feature of the initial microstructure, deformed microstructures, and the fractured surface were characterized using Zeta-20 optical microscopy (OM) and a Hitachi SU-70 field-emission scanning electron microscopy (SEM).

\section{RESULTS \& DISCUSSION}

\section{Powder characterization}

The SEM images of the powder particles used to fabricate the EBM-Ti-6Al-4V is shown in Fig.3. The average size of the powder particles was $55.38 \mu \mathrm{m}$, with the minimum and maximum diameter of $38.1 \mu \mathrm{m}$ and $97 \mu \mathrm{m}$, respectively.

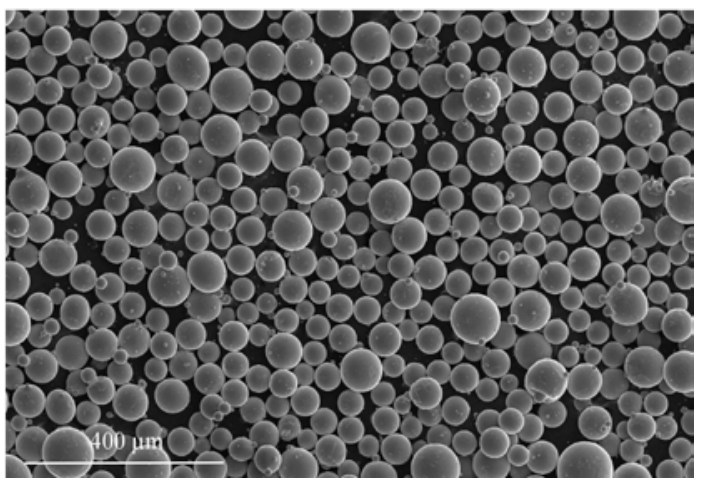

Figure 3- SEM image of the Grade $5 \mathrm{Ti}-6 \mathrm{Al}-4 \mathrm{~V}$ powder revealing the size of the particles.

\section{Initial microstructure}

$\mathrm{OM}$ and SEM images of the typical initial microstructure of the horizontally built EBM-Ti-6Al-4V rods are shown in Fig. 4(a) and 4(b), respectively. Prior $\beta$-grain boundaries that are almost parallel to the building direction (x-axis) are marked on the OM image. The microstructure depicts the transformed $\alpha+\beta$ structure. In the SEM image, bright regions correspond to the $\beta$-phase, and dark regions represent the $\alpha$ phase. $\beta$-phase in the morphology of flat rods and the presence of grain boundary $\alpha$ along the prior $\beta$-grain boundary are the most significant microstructural features in the EBM-Ti-6Al-4V samples.

\section{Dynamic behavior of EBM-Ti-6Al-4V}

The stress-strain curves of the samples that underwent three different strain rates $\left(690 \mathrm{~s}^{-1}, 1580 \mathrm{~s}^{-1}\right.$, and $2220 \mathrm{~s}^{-1}$ ) are shown in Fig. 5. Each curve is the average of three curves. The dynamic compression behavior of these samples exhibits an initial strain hardening, and then a gradual increase in the rate of hardening followed by thermal softening in the end. With the rise in the strain rate, ultimate compressive strength (UCS) and strain-to-fracture increased. On average, 48\%, 28\%, and 286\% improvement was observed in yield strength, UCS, and strain-to-fracture by increasing the strain rate from $690 \mathrm{~s}^{-1}$ to $2220 \mathrm{~s}^{-1}$. 


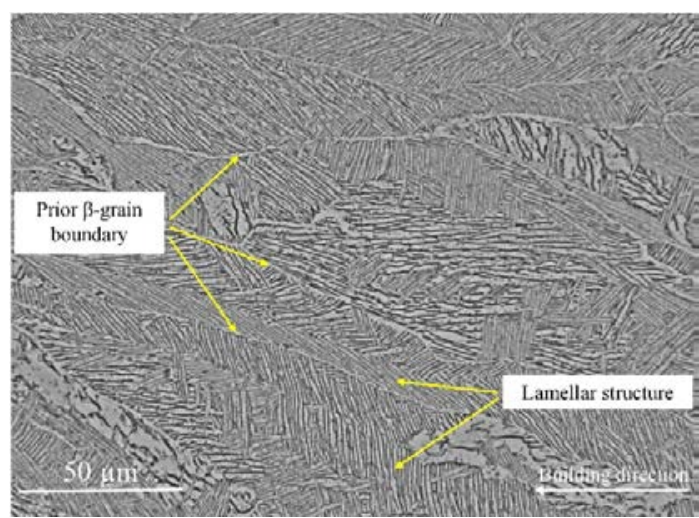

(a)

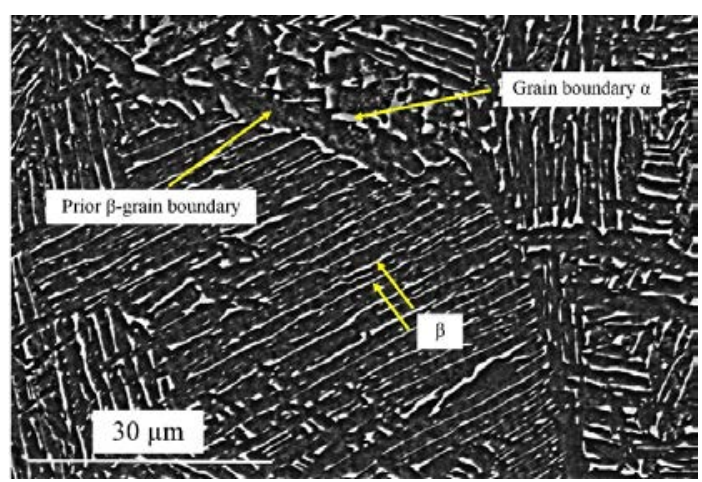

(b)

Figure 4- (a) OM and (b) SEM image of the EBM-Ti-6Al-4V typical initial microstructure.

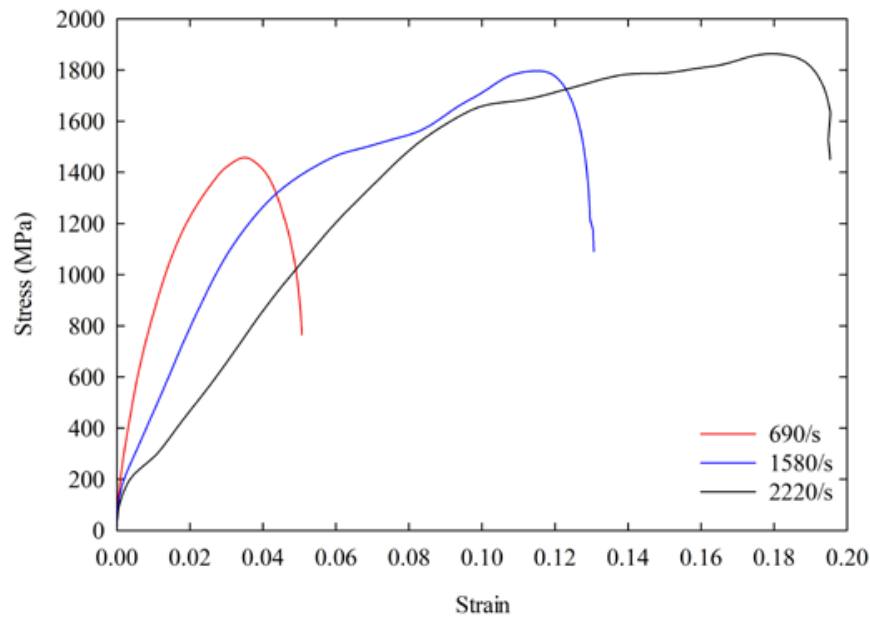

Figure 5- Typical compressive stress-strain curves of horizontally printed EBM-Ti-6Al-4V samples.

\section{Deformed microstructure}

SEM images of the deformed microstructures of EBM-Ti-6Al-4V samples for the strain rates correspond to 690 $\mathrm{s}^{-1}$, and $1580 \mathrm{~s}^{-1}$ are shown in Figs. 6(a) and (b), respectively. It can be seen that the interlamellar spacing decreased from $1.2 \mu \mathrm{m}$ to $0.4 \mu \mathrm{m}$ by increasing the strain rate., The decrease in the spacing increases the strength due to the presence of more obstacles for the movement of dislocations, as per the Hall-Petch equation [11] given below:

$$
\sigma_{Y S}=\sigma_{0}+K \frac{1}{\sqrt{\delta}}
$$

where $\sigma_{\mathrm{YS}}, \sigma_{0}, \mathrm{~K}$, and $\delta$ are yield strength, internal strength, dislocation locking constant, and interlamellar spacing/ $\alpha$-lath thickness. It is also observed that $\alpha$-lamellae tend to fragment when the strain rate is increased.

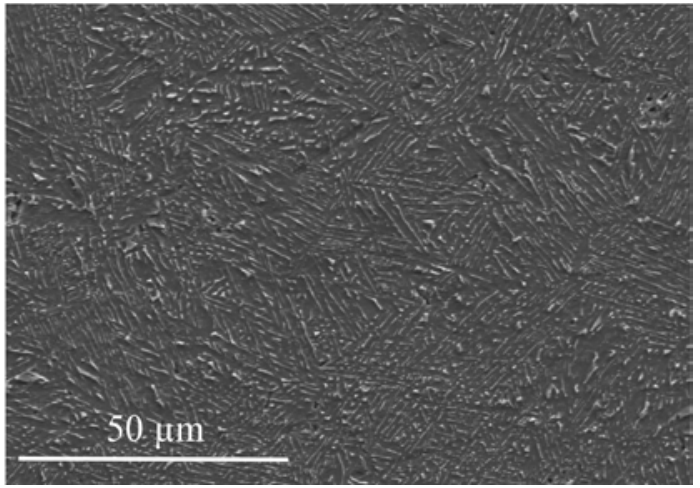

(a)

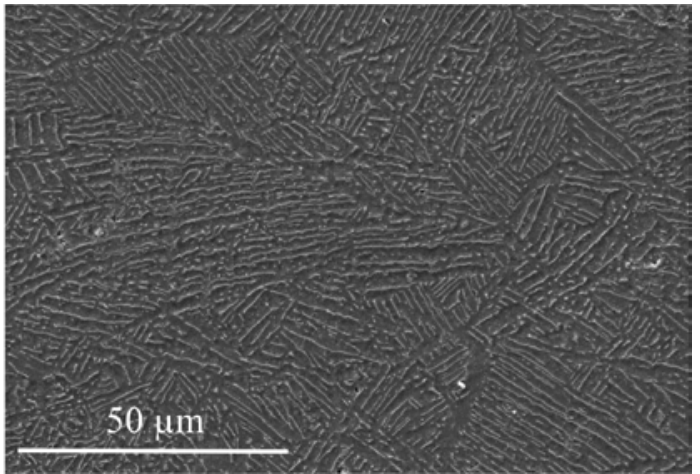

(b)

Figure 6- SEM images of the deformed microstructures of the samples compressed at the strain rates of (a) $690 \mathrm{~s}^{-1}$ and (b) $1580 \mathrm{~s}^{-1}$.

ASBs were observed in the samples deformed at the strain rate of $1580 \mathrm{~s}^{-1}$ (shown in Fig. 7). ASB formation is known as one of the main mechanisms of deformation and failure at high strain rates, which forms due to the shear stress localization [12]. Typically, in titanium alloys, thermal instability occurs in some bands due to the low thermal conductivity of titanium that leads to the transformation of deformation energy to thermal energy [13]. Figs. 7(a-c) shows different steps involved from the formation of ASB to the crack propagation. In Fig. 7(a) three regions of ASBs can be observed, and the formation of a crack can be seen at the top-right corner of the image. The microstructure of ASB presented in Fig. 7(b) is a highmagnification image of region 1 in Fig. 7a, where there are no distinct features, and the formation of the shear band, is a result of dynamic recrystallization.

The localization of shear stress facilitates the formation of voids. The failure mechanism through the formation of the ASBs can be divided into multiple stages. In the first stage, voids nucleate due to the presence of tensile stress in the ASB 
areas, followed by their growth due to the localization of shear stress in the second stage. In the next stage, with the continuation of deformation, void coalescence occurs, leading to the formation of crack and subsequent propagation, leading to fracture. Fig. 7(c) shows the typical features of voids formation and their coalescence.

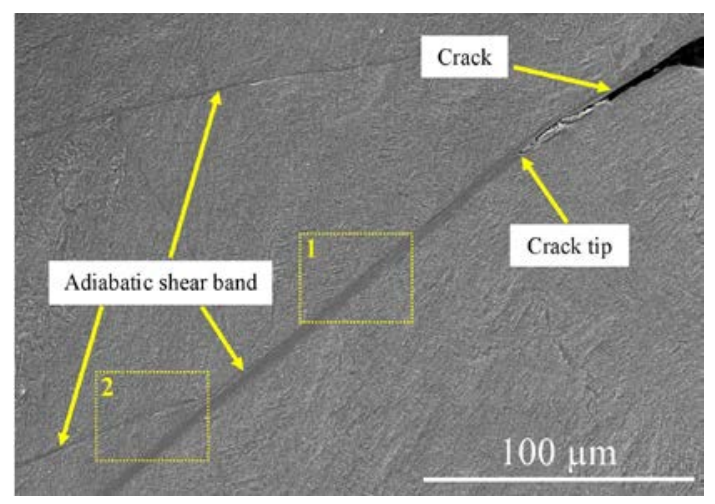

(a)

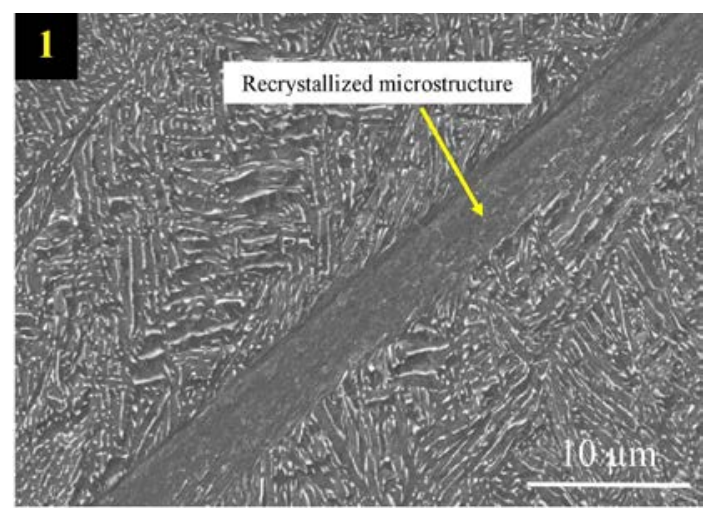

(b)

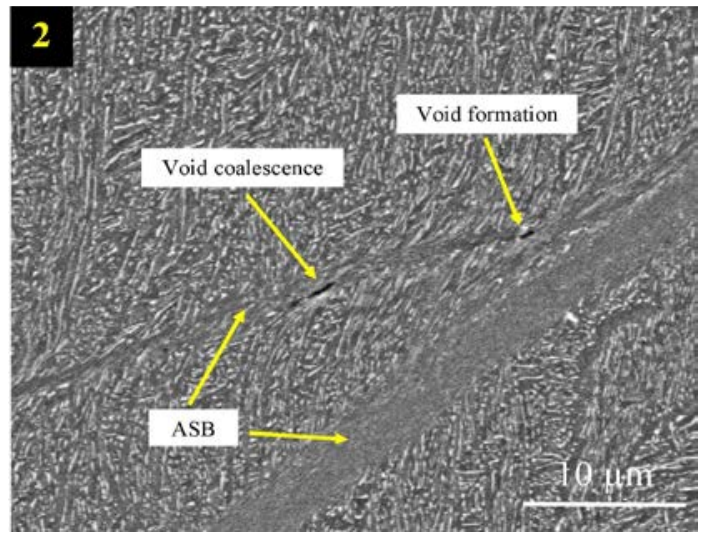

(c)

Figure 7- SEM micrographs of sample deformed at $1580 \mathrm{~s}^{-1}$ revealing (a) formation of ASB and cracking, (b) features of ASB, and (c) void formation and coalescence in an ASB.

The fracture surface of the sample deformed at the strain rate of $2195 \mathrm{~s}^{-1}$ is shown in Fig. 8. The surface reveals smooth surfaces, which indicates that the nature of the failure is brittle.
However, in some regions, features of dimples were also seen as shown in Fig. 8(b). It can be concluded that the deformation (strain-to-fracture) at higher strain rates is due to the flowinduced softening. The formation of shear bands and the accompanying adiabatic shear failure led to the fracture of the alloy under impact loading.

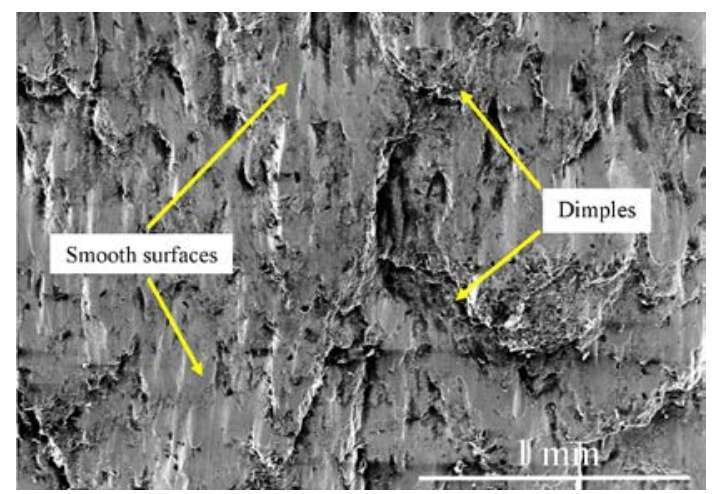

(a)

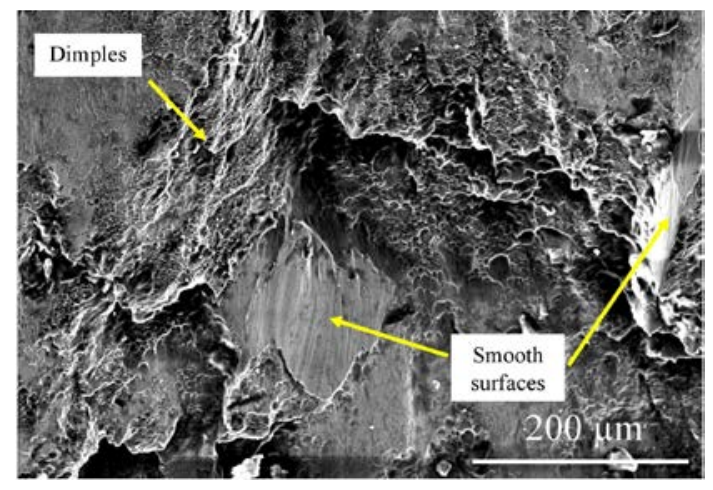

(b)

Figure 8- SEM micrographs of the fracture surface of the deformed sample tested at the strain rate of $2195 \mathrm{~s}^{-1}$.

\section{CONCLUSION}

In this study, the effect of strain rate on the microstructure, dynamic compressive properties, and deformation mechanisms of horizontally built EBM-Ti-6Al-4V cylindrical rods was investigated using a SHPB apparatus. The outcomes of this research are listed below:

1. The initial microstructure of the as-printed sample consists of columnar $\beta$-grains along the building direction and the presence of grain boundary $\alpha$ along the prior $\beta$-grain boundaries.

2. Mechanical properties increased by increasing strain rate. UTS, YS, and ductility increased by $28.1 \%, 48.7 \%$, and $286 \%$ by increasing the strain rate from $690 \mathrm{~s}^{-1}$ to $2220 \mathrm{~s}^{-1}$.

3. Microstructure refinement that includes decrease in interlamellar spacing, and lamellae fragmentation were observed in the samples deformed at higher strain rates. 
4. ASBs, as one of the main deformation mechanisms, were observed in the microstructure of the sample deformed at $1580 \mathrm{~s}^{-1}$. The void formation, coalescence, crack formation and propagation along the ASBs led to the fracture of the specimens.

5. The fracture surface showed a mixture of smooth cleavage fracture and ductile fracture characters by the presence of dimples.

\section{AKNOWLEDGEMENT}

The authors would like to thank Natural Sciences and Engineering Research Council of Canada (NSERC) grant number RGPIN-2016-04221, New Brunswick Innovation Foundation (NBIF) grant number RIF2017-071, Atlantic Canada Opportunities Agency (ACOA)- Atlantic Innovation Fund (AIF) project number 210414, Mitacs Accelerate Program grant number IT10669 for providing sufficient funding to execute this work. The authors acknowledge the GE/Arcam in Woburn, MA, USA for fabricating the Ti-6Al$4 \mathrm{~V}$ cylinders via EBM. Thanks are due to Brian Guidry at UNB-Mechanical Engineering for sample preparation and, Dr. Douglas Hall and Steven Cogswell at UNB's Microscopy and Microanalysis Facility for SEM.

\section{REFERENCES}

[1] Ivasyshyn, O. M., \& Aleksandrov, A. V. (2008). Status of the titanium production, research, and applications in the CIS. Materials Science, 44(3), 311-327.

[2] C. Cui, B. Hu, L. Zhao, S. Liu, Titanium alloy production technology, market prospects and industry development, Mater. Des. 32(3) (2011) 1684-1691.
[3] Gurappa, I. (2003). Protection of titanium alloy components against high temperature corrosion. Materials Science and Engineering: A, 356(1-2), 372-380.

[4] DebRoy, T., Wei, H. L., Zuback, J. S., Mukherjee, T., Elmer, J. W., Milewski, J. O. ... \& Zhang, W. (2018). Additive manufacturing of metallic components-process, structure and properties. Progress in Materials Science, 92, 112-224.

[5] Vayssette, B., Saintier, N., Brugger, C., Elmay, M., \& Pessard, E. (2018). Surface roughness of Ti-6Al-4V parts obtained by SLM and EBM: effect on the high cycle fatigue life. Procedia engineering, 213, 89-97.

[6] Dharmendra, C., Hadadzadeh, A., Amirkhiz, B. S., Lloyd A, \& Mohammadi, M. (2020). Deformation mechanisms and fracture of electron beam melted Ti-6Al-4V. Mater. Sci. Eng. A. 771 (2020) 138652.

[7] Dharmendra, C., Alaghmandfard, R., Hadadzadeh, A., Amirkhiz, B. S., \& Mohammadi, M. (2019). Influence of build orientation on small-scale properties of electron beam melted Ti-6Al-4V. Materials Letters, 126970.

[8] C.-F. L. Woei-Shyan Lee *, "Plastic deformation and fracture behaviour of Ti-6Al-4V alloy loaded with high strain rate under various temperatures," States News Serv., vol. 241, pp. 48-59, 1998.

[9] Z. Me-Bar, Y., Rosenberg, "On The Correlation Between The Ballistic Behavior Dynamic Properties of Ti Alloy Plates,” vol. 19, no. 4, pp. 311-318, 1997.

[10] Weinong, W., \& Chen, B. S. (2011). Split Hopkinson (Kolsky) bar: Design, testing and applications. Mechanical Engineering Series, 1.

[11] Lapin, J., \& Nazmy, M. (2002). Directional solidification of intermetallic Ti-46Al-2W-0.5 $\mathrm{Si}$ alloy in alumina moulds. Intermetallics, 10(10), 1019-1031.

[12] Zheng, C., Wang, F., Cheng, X., Liu, J., Liu, T., Zhu, Z., \& Jin, D. (2016). Capturing of the propagating processes of adiabatic shear band in Ti-6Al-4V alloys under dynamic compression. Materials Science and Engineering: A, 658, 60-67.

[13] Meyers, M. A., Subhash, G., Kad, B. K., \& Prasad, L. (1994). Evolution of microstructure and shear-band formation in $\alpha$-hcp titanium. Mechanics of Materials, 17(2-3), 175-193. 